\title{
ENCINARES LUSO-EXTREMADURENSES Y SUS ETAPAS PRECLIMACICAS
}

\author{
Miguel LADERO, José Luis PEREZ CHISCANO, Maria Teresa SANTOS, \\ Cipriano Jesús VALLE \& Angel AMOR
}

RESUMEN: Se comentan las distintas faciaciones de encinar observadas en la provincia corológico luso-extremadurense, dentro de la serie mesomediterráneo de la encina o Quercus rotundifolia Pyro-Querceto rotundifoliae sigmetum.

Palabras clave: Encinares, Pyro-Querceto rotundifoliae S., provincia Luso-Extremadurense (España).

SUMMARY: We comment several faciations holm-oak wood's of the Luso-Extremadurense province belonging to the mesomediterranean series Pyro-Querceto rotundifoliae S.

Key words: Holm-oak woods, Pyro-Querceto rotundifoliae S., Luso-Extremadurense province (Spain).

Los encinares ocupan potencialmente el setenta por ciento de la superficie provincial. Ante una extensión tan grande es evidente que tienen que existir distintos tipos de encinares como consecuencia de las variaciones bioclimáticas, geológicas, edafológìcas, dinámicas e históricas. Los más extendidos corresponden a la serie mesomediterránea luso-extremadurense silicícola de la encina (Quercus rotundifolia) Pyro bourgaeanae-Querceto rotundifoliae S. la cual está definida por los siguientes parámetros: se presenta en penillanuras sobre suelos poco profundos, formados a partir de pizarras cámbricas y precámbricas; ocupa áreas mesomediterráneas inferiores y medias; el ombroclima está comprendido entre el seco inferior y el subhúmedo y el índice de mediterraneidad $\mathrm{Im}_{2}$, se encuentra situado entre valores de 15 a 35.

Desde el punto de vista biogeográfico ocupa, dentro del sector ToletanoTagano, la casi totalidad del subsector cacereño, en el subsector oretano el distrito jareño y en el subsector talaverano-placentino los distritos alberchense y talaverano; en el sector Mariánico-Monchiquense gran parte del distrito Serena-Pedroches, donde quedan incluidas comarcas naturales tan características como los valles de La Serena, Alcudia, Los Pedroches, Alto Guadiato y el límite sur de los Campos de Calatrava y Santiago. 
Como peculiaridades más destacadas en cuanto a su vegetación es digna de ser consignada la etapa preclimácica formada por un matorral denso de matas de encina, a lo que Pérez Chiscano (1976:225) denominó "mata parda"; esta formación se ve favorecida en las dehesas dedicadas a la explotación ganadera por el embastecimiento de majadales y posíos. En estos medios con un grado de cobertura muy elevado por parte del estrato herbáceo, formado fundamentalmente de gramíneas y papilionáceas, la germinación del fruto es muy escasa o nula y por el contrario adquieren gran vigor los tallos surgidos de las yemas radicales, de aquí los típicos corros que rodean a las encinas adultas. Tienen un papel importante en la catalogación de estos encinares, los retamares con retama negra (Cytiso scoparii-Retametum) en el sector mariánicomonchiquense y las formaciones similares con escobas blancas pertenecientes a la subasociación cytisetosum multiflori en el sector toletano-tagano. Son típicos de esta serie los ahulagar-jarales de Genisto-Cistetum ladaniferi, los tomillares de Scillo-Lavanduletum sampaianae y los típicos majadales de Poo-Trifolietum subterranei.

Dentro del encinar luso-extremadurense diferenciamos varias faciaciones que pasamos a comentar y definir.

\section{1.- Faciación termófila toletano-tagana de Olea sylvestris}

A lo largo de los ríos servidores del Tajo que presentan al llegar a la penillanura bien definido el proceso de encajamiento formando los típicos "riberos", detectamos la presencia de elementos termófilos, como consecuencia de ciertos valores climáticos $(\mathrm{H}, \mathrm{Pav})$, dando lugar a la existencia de unas formaciones vegetales que denominamos acebuches. Se trata de comunidades permanentes de solana, desarrolladas sobre litosuelos, donde la encina ha desaparecido y su lugar lo ocupa el olivo. La vegetación característica es el acebuchal de Asparago-Rhamnetum oleoidis (spiculosae) y como etapas seriales propias destacamos: los pastizales vivaces denominados "cerrillares" de Dauco-Hyparrhenietum hirtae asentados sobre los litosoles y regosoles, los pastizales terofíticos subnitrófilos de la Bromo tectoriStipetum capensis y la comunidad escionitrófila de la Torili nodosae-Parietarietum lusitanicae, protegidas unas veces por los olivos y otras por las lajas en forma de "dientes de perra". Esta última comunidad también la hemos visto en algunas solanas a la sombra de las calizas cámbricas en Almaraz y Valdecañas, enriquecida con algún elemento específico como Torilis arvensis subsp. elongata.

La distribución sincorológica de este sintaxon es prácticamente toletanotagana, subsector cacereño, distritos jareño y alberchense. En el sector MariánicoMonchiquense se presenta en solanas abrigadas de los valles de Alcudia y Alto Guadiato dentro del distrito Serena-Pedroches.

\section{2.- Faciación psamófila toletano-tagana de Quercus suber}

Se corresponde con los encinares con alcornoques desarrollados sobre arenosoles (Ruiz Téllez, 1988:2) que en muchas ocasiones, por su explotación forestal, se presentan como alcornocales puros; son dehesas arboladas de escasa producción pascícola, de aquí su orientación forestal. De entre las comunidades más características destacamos los jaguarzales de Halimietum commutati -hoy casi en extinción y sólo conservados en el término de Velada (Toledo)- los "codesales 
cenicientos" de marcado carácter viario pertenecientes a la asociación Lavandulo sampaianae-Adenocarpetum aurei, los pastizales terofíticos de Anthyllido hamosaeMalcolmietum patulae y los pastizales subnitrófilos de Chamaemeli mixtiVulpietum alopecuroidis. El areal de esta formación vegetal queda restringido a los distritos arañuelense y talaverano.

Al comprobar la existencia de las comunidades herbáceas en el arenal de Villanueva-Mengabril, surge la duda de si estos arenales albergaron en otro tiempo encinares con alcornoques semejantes a los aquí comentados.

\section{3.- Faciación granitícola toletano-tagana de Quercus suber}

Corresponde a los encinares con alcornoques desarrollados entre berrocales graníticos donde los suelos son mucho más compactos (regosoles y luvisoles). En el momento actual quedan algunos alcornoques añosos refugiados entre los bloques graníticos, siendo la comunidad más representativa la de los escobonales blancos de Cytiso multiflori-Retametum sphaerocarpae, en continua expansión como consecuencia de los fuegos periódicos buscando el aumento de pastizales temporales. Para nosotros esta comunidad de escobonal ha servido, desde el punto de vista biogeográfico, para incluir los "baldíos de Alburquerque" dentro del sector toletanotagano (Ladero \& cols. 1987:466). También queremos destacar aquí la presencia en esta faciación de Adenocarpus complicatus subsp. commutatus. Como comunidad escionitrófila, a la sombra de los bloques graníticos, se cobija la AnogrammoParietarietum lusitanicae, donde tiene su nicho Scrophularia schousboei.

La distribución de este sintaxon está ligada a los afloramientos graníticos, por tal motivo se encuentra en el subsector cacereño, en el límite meridional del distrito arañuelense, en el afloramiento granítico de Villar del Pedroso del distrito jareño y en el batolito de la umbría de Valcorchero, distrito placentino.

\section{4.- Faciación basifila toletano-tagana}

Corresponde a encinares desarrollados en los afloramientos y sedimentos calizos repartidos por el sector toletano-tagano (Santos, Ladero \& Amor, 1989). Las calizas tienen distintos orígenes destacando las paleozoicas y, en menor proporción, los sedimentos miocenos; se encuentran ubicadas en áreas térmicas y distantes.

Presentan la fase de espinal preclimácico de Asparago-Rhamnetum spiculosae cocciferetosum, pero sobre todo destaca el "jaral blanco" de Lavandulo-Cistetum albidi, que al envejecer se transforma en el ahulagar-jaral de Genisto-Cistetum ladaniferi. Sirven de refugio a los pastizales terofíticos basófilos de Velezio rigidaeAsteriscetum aquaticae, siendo notable en primavera la gran riqueza en orquídeas.

El area mayor se encuentra en el subsector Oretano, distrito Villuerquino (calizas cámbricas de Almaraz-Valdecañas de Tajo-Romangordo y valle del Ibor). En el distrito Sampedrino destacan las calizas carboníferas de Valdelasyeguas, Valdealiso y Valdelacasa y, en el subsector cacereño, las calizas carboníferas de Cáceres y los sedimentos miocenos de Torrejón el Rubio y Coria.

Debemos señalar finalmente la pobreza en elementos basófilos de estos afloramientos frente a los del subsector manchego-sagrense que llegan hasta casi el corazón de Campo Arañuelo. Entendemos que en gran medida esta pobreza está ligada 
a la dureza de las calizas paleozoicas frente a los sedimentos calizos miocenos de la Meseta inferior.

\section{5.- Faciación termófila silicícola mariánico-monchiquense de Pistacia lentiscus}

Se encuentra asentada sobre suelos procedentes de rocas silíceas: pizarras, granodioritas y sedimentos pliocenos de textura arenosa; corresponden a lo que Pérez Chiscano (1976:224) denomina "charnecales". Está marcada por un mayor índice de termicidad, así como valores más altos de parámetros bioclimáticos como $\mathrm{H}, \mathrm{Pav}$ y tipo de invierno. Esto se traduce en la existencia de un encinar con "charnecas" o mejor de un "charnecal", donde tienen cabida plantas termófilas como Olea europaea var. sylvestris, Rhamnus lycioides subsp. spiculosa y en menor proporción Asparagus albus o Quercus coccifera. Según Pérez Chiscano (1976) estas altifruticetas de penillanura y faldas inferiores de las sierras oretano-mariánicas pueden ser consideradas como Phillyreo-Arbutetum pistacietosum lentisci. Debido a la destrucción masiva de estas formaciones vegetales, se instala el ahulagar-jaral termófilo de Genisto hirsutae-Cistetum ladaniferi cistetosum monspeliensis.

La distribución de esta faciación queda casi circunscrita al sector MariánicoMonchiquense; su presencia en el sector Toletano-Tagano se reduce a ciertas solanas muy térmicas de las sierras oretanas sobre derrubios de ladera, ya que la aparición de las pizarras cámbricas da paso a la instalación de los acebuchales. Como ejemplo de lo que aquí comentamos destacaremos, por el carácter relicto, la solana de la Sierra de La Garrapata junto a Monfortiño (Portugal), el Barranco de la Ramira en la Sierra de Altamira (Peraleda de San Román) y el charnecal de la Sierra de Serrejón. En cuanto a su distribución geográfica, destacar la amplitud que ocupa en los subsectores Marianense y Araceno-Pacense.

\section{6.- Faciación basifila de Tierra de Barros con Quercus coccifera}

Ninguna otra faciación es más controvertida que ésta ya que, para nosotros, los encinares que se desarrollan sobre los "barros" y luvisoles crómicos del distrito corológico de Tierra de Barros no son otra cosa que una faciación de los encinares luso-extremadurenses de la serie Pyro-Quercetum rotundifoliae sigmetum. RivasMartínez (1987) incluye estas formaciones en la serie mesomediterránea bética basifila de Quercus rotundifolia (Paeonio coriaceae-Querceto rotundifoliae sigmetum).

Nuestros argumentos después de haber recorrido intensamente los afloramientos básicos de la provincia de Badajoz, los resumiremos de la siguiente forma: la asociación de tomillar Helianthemo-Saturejetum micranthae, que es uno de los pilares más sólidos para apoyar la serie bética dentro de nuestro territorio, es sin duda alguna la más desviante y empobrecida de toda la alianza SaturejoCoridothymion. De los elementos que entran a formar parte de esta comunidad según Rivas Goday \& Rivas-Martínez (1968: tab. 22), existen plantas como Sideritis hirsuta subsp. hirtula, Helianthemum hirtum subsp. bethuricum, que para nosotros son endemismos; en cuanto a Teucrium lusitanicum es posible que se trate de un nuevo taxon derivado de Teucrium haenseleri y visto por nosotros en la Sierra de Aracena. Si consideramos dentro de Micromeria graeca la var. micrantha, su distribución es mariánico-monchiquense; no se conoce ninguna cita de Thymbra 
capitata en este distrito corológico, taxon al que consideramos como el elemento más característico de la alianza.

En el momento actual se conservan encinares perfectamente desarrollados dentro de esta unidad biogeográfica, como es el caso de la Sierra de Monsaluz. En las sierras de María Andrés y Bienvenida, se encuentran muy bien conservados madroñales y coscojares, pero en ninguna de esas áreas hemos observado Paeonia coriacea, tan abundante por otra parte en la serie bética de las provincias de Granada, Jaén o Málaga. Cuando estos encinares son destruídos, se instala un jaral blanco de Cistus albidus, que corresponde a lo que Rivas Goday (1964:457) denominó comunidad de Cistus albidus, o un coscojar enriquecido en elementos termófilos como Pistacia lentiscus, Myrtus communis, Olea europaea var. sylvestris, Phlomis purpurea y Ononis speciosa; únicamente hemos visto un elemento meseteño y bético: Colutea arborescens. Para nosotros la etapa preclimácica podría estar muy cerca del charnecal silíceo de Phillyreo-Arbutetum pistacietosum lentisci, diferenciándose por la gran abundancia de Quercus coccifera, frente a la faciación silicícola termófila mariánico-monchiquense comentada con anterioridad. Al analizar los encinares mesomediterráneos béticos de Paeonio-Quercetum rotundifoliae y sus etapas seriales, destacaríamos la gran importancia diferencial que tienen los matorrales de la alianza Lavandulo-Echinospartion boissieri y los retamares de Genisto speciosae-Retametum, totalmente ausentes de nuestro territorio. La influencia del sector hispalense y por ende de las comunidades del orden Phlomidetalia purpureae son escasas; de los elementos propios del orden sólo hemos encontrado Ononis speciosa, ya que Phlomis purpurea, consignado como característico de orden, resulta indiferente edáfico, ligado más a la termicidad que al carácter del suelo sobre el que se desarrolla.

Finalmente hemos de sañalar que la Paeonio-Quercetum rotundifoliae (subbética, malacitano-almijarense y rondeña) queda interrumpida en el valle del Guadalquivir sobre suelos básicos por la serie termomediterránea bético-algarviense, seco-subhúmedo-húmeda, basófila, de Quercus rotundifolia (Smilaco mauritanicaeQuerceto rotundifoliae S.) típicamente hispalense.

Por todo lo anteriormente expuesto consideramos que los encinares basifilos del distrito de Tierra de Barros, deben ser considerados como una faciación basifila cocciferetosum de la serie luso-extremadurense mesomediterránea de la encina PyroQuerceto rotundifoliae S.

Una de las razones que Rivas-Martínez (l.c.) aduce para situar estos encinares dentro de la serie bética, es la presencia de los tobarales de Dauco maximiNotobasietum syriaceae; entendemos que estos cardales están ligados no sólo al sustrato sino sobre todo a la nitrofilia, de aquí que no pueda ser considerada esta comunidad como definitoria de una serie de vegetación.

7.- Por último queremos hacer un pequeño comentario de la faciación silicícola psamófila del encinar de ombroclima subhúmedo medio, en la cual es característica la presencia masiva de Quercus pyrenaica; aparece sobre arenosoles con capas freáticas poco profundas como consecuencia de zonas de acumulación de limos que impermeabilizan el subsuelo formando bolsas de agua. Esta faciación se encuentra intermedia entre la faciación psamófila del alcornoque y los robledos luso- 
extremadurenses de Arbuto-Quercetum pyrenaicae. La distribución de esta faciación queda reducida a las áreas próximas al río Tiétar y al arroyo de Santa María en el término de Talayuela (Cáceres), dentro del distrito arañuelense.

Los encinares pertenecientes a la serie termomediterránea mariánicomonchiquense y bética, seco-subhúmeda, silicícola de la encina Myrto-Querceto rotundifoliae $\mathrm{S}$. corresponden a bosques densos de encinas con un elevado número de elementos termófilos: Chamaerops humilis, Aristolochia baetica, Osyris quadripartita, Rhamnus oleoides subsp. oleoides, como señala Rivas-Martínez (1987:165).

Esta serie, que no hemos encontrado en la provincia de Badajoz, ocupa áreas extensas en las de Sevilla y Huelva. Sus etapas de degradación pasan primero por un madroñal con mirtos (Phillyreo-Arbutetum myrtetosum) en los suelos más profundos y, en los suelos más pedregosos, por un espinal de Asparagö-Rhamnetum oleoidis myrtetosum. Al continuar la degradación de los suelos se instalan jarales de Genisto-Cistetum ladaniferi cistetosum monspeliensis, la presencia de esta comunidad requiere suelos más esqueléticos, aumentando su frecuencia al dirigirnos hacia el oeste.,

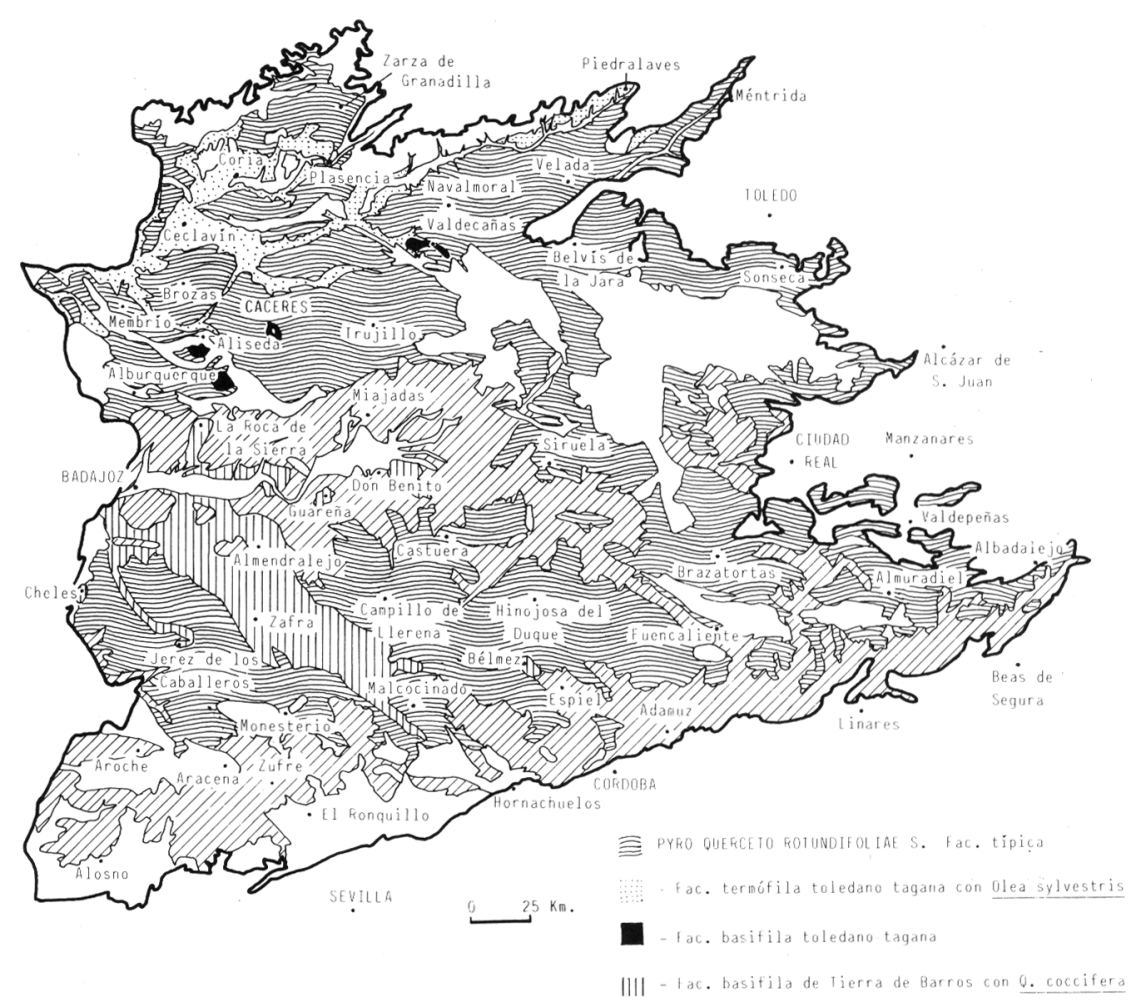




\section{B I B L I O G R A F I A}

LADERO, M., PEREZ CHISCANO, J.L. \& AMOR, A. -1987- España Lusoextremadurense. pp.: 453-486. In: La vegetación de España. M. Peinado Lorca \& S. Rivas Martínez, Eds. Serv. de Publ. Univ. de Alcalá de Henares.

PEREZ CHISCANO, J.L. -1976- Charnecales y madroñales del noreste de la provincia de Badajoz. Anal. Inst. Bot. Cavanilles, 33:219-238. Madrid.

RIVAS GODAY, S. -1964-Vegetación y Flórula de la cuenca extremeña del Guadiana. Publ. Excma. Dip. Prov. de Badajoz. Madrid.

RIVAS GODAY, S. \& RIVAS MARTINEZ, S. -1968- Matorrales y tomillares de la Península Ibérica, comprendidos en la clase Ononido-Rosmarinetea. Anal. Inst. Bot. Cavanilles, 24:7-180. Madrid.

RIVAS MARTINEZ, S. -1987- Memoria del Mapa de Series de Vegetación de España. Hojas 17 y 22. I.C.O.N.A. Madrid.

RUIZ TELLEZ, T. -1988-Vegetación del tramo medio del Valle del Tiétar y el Campo Arañuelo. Ed. Inst. Cultural "El Brocense", Excma. Dip. Prov. de Cáceres, 47 pp.

SANTOS, M.T., LADERO, M. \& AMOR, A. -1989- Vegetación de las intercalaciones básicas de la provincia de Cáceres (Extremadura, España). Stvdia Botanica, 7:9-147. Salamanca.

(Aceptado para su publicación el 13 de febrero de 1990)

Dirección de los autores: M. LADERO, M.T. SANTOS, C.J. VALLE \& A. AMOR: Departamento de Biología Vegetal (Botánica), Facultad de Farmacia, Salamanca. J.L. PEREZ CHISCANO: Villanueva de la Serena, Badajoz. 
